\title{
Physical, Mechanical and Microstructural Characteristics of Cement-Locust Bean Pod Ash Mortar Blend
}

\section{*11AKPENPUUN, TD; ${ }^{2}$ AKINYEMI, BA; ${ }^{3}$ OLAWALE, O; ${ }^{4}$ ALADEGBOYE, OJ; ${ }^{1}$ ADESINA, OI}

\author{
${ }^{I}$ Department of Agricultural and Biosystems Engineering, University of Ilorin \\ ${ }^{2}$ Department of Agricultural and Biosystems, Engineering, ${ }^{3}$ Department of Chemical Engineering, ${ }^{4}$ Department of Civil Engineering, \\ Landmark University Omuaran, Nigeria \\ *Corresponding author Email: akpenpuun.td@unilorin.edu.ng
}

\begin{abstract}
The need to reduce the environmental pollution resulting from agro-wastes and to source a material that can be used to replace cement in order to reduce the pressure on its consumption necessitated this research. This study evaluated the effect of cement replacement with locust bean pod ash (LBPA) as supplementary cementitious material on the mechanical properties of mortar. The physical properties (workability, initial and final setting times), the compressive strength at 7, 14,21 and 28 days and microstructural analysis (SEM, EDS, and XRD) were investigated. LBPA were considered at replacement levels of 0, 10, 15, 20 and 30\% of cement mass for preparation of the mortar samples. Workability of the cement mortars reduced as the content of LBPA increases, while initial and final setting times increased with a correspnding rise in LBPA content in the matrix. An increase of about $79 \%$ in compressive strength at 7 days, $100 \%$ at 14 days, $147 \%$ at 21 days and $136 \%$ at 28 days were recorded with LBPA content of 15\% LBPA being the optimum level when compared to control mix. Maximum compressive strength increased with the number of days of curing and ranged between 38.3 and $65 \mathrm{MPa}$. Microstructural analysis revealed fewer voids and pores, and the presence of dense Calcium silicate hydrate (C-S-H) gels which helped to maintain the optimum compressive strength at 15\% LBPA cement replacement level of the mortar.
\end{abstract}

\section{DOI: https://dx.doi.org/10.4314/jasem.v23i3.1}

Copyright: Copyright (C) 2019 Akpenpuun et al. This is an open access article distributed under the Creative Commons Attribution License (CCL), which permits unrestricted use, distribution, and reproduction in any medium, provided the original work is properly cited.

Dates: Received: 17 November 2018; Revised: 19 January 2019; Accepted 22 January 2019

Keywords: compressive; strength; agro-waste; pod; ash

Population growth in most developing nations has led to an astronomical increase in demand for cement. Therefore to meet this demand, cement productions have been jerked up with its accompanying carbon emissions (Omoniyi and Akinyemi, 2012; Adama and Jimoh, 2012). Supplementary cementitious materials (SCM) have been proffered as the solution to this problem through its effective and successful use in construction materials. The adoption of SCM in construction leads to a significant reduction in carbon emissions into the environment. They are also known as pozzolans, and if used in combination with cement, they form cementitious particles, but alone without combination with cement, they do not have cementitious elements. SCMs' such as rice husk ash, fly ash, blast furnace slag, as well as silica fume amongst others, have been utilised (Röbler et al., 2013; Mahmud et al., 2016; Akpenpuun et al., 2017). Nonetheless, the accessibility of these substances is limited to specific locations and industrialization, Therefore it is imperative that focus must be shifted to conducting studies on SCM's emanating from agriculture more than others because of its abundance and availability in most parts of the world (ASTM E986 - 04, 2017). Other agricultural waste materials used as SCMs include wood waste, bamboo leaf ash, and corncob ash. Minimal attention is paid to locust bean pod as another prospective pozzolan in cement for building applications being an agricultural waste material. Locust bean tree (Parkia biglobosa) is a deciduous tree which grows in Sub Saharan Africa. The pod is usually opened up to remove the pulp and the seeds encased within it. After that it is discarded, burnt and the ashes dumped in landfills (Tangchirapat et al., 2009; Adama and Jimoh, 2012). Limited studies had been conducted on its use as supplementary cementitious materials in concrete and majority of these studies were paid no attention to microstructural analysis such as SEM, EDS, XRD and nonuse of superplasticizers which would have improved the workability of the mortars produced (Röbler et al., 2013). In this present experiment, the performance of locust bean pod ash blended cement on workability; setting time and compressive strength of mortars was 
evaluated while incorporating superplasticizer. Similarly, the use of SEM, EDS and XRD was used to perform further analysis to determine the internal networks and the crystalline materials located within the samples.

\section{MATERIALS AND METHODS}

Locust bean pod ash (LBPA): The waste was obtained from a farm around the University environment. Sorting was done by removing unwanted organic materials such as leaves, shrubs, and stalks. LBPA was sun-dried for two weeks until the change in moisture content was $0 \% .10 \mathrm{~kg}$ of it were then calcined in a muffle furnace at $600^{\circ} \mathrm{C}$ with a heating rate of $40^{\circ} \mathrm{C} / \mathrm{min}$ for 2 hours and 2 hours retention time. The obtained ashes were ground manually for 4 minutes and the particle size analysis was done as shown in Figure 1. According to ASTM C 618 standard and classified as Class $\mathrm{C}$ pozzolanic material.

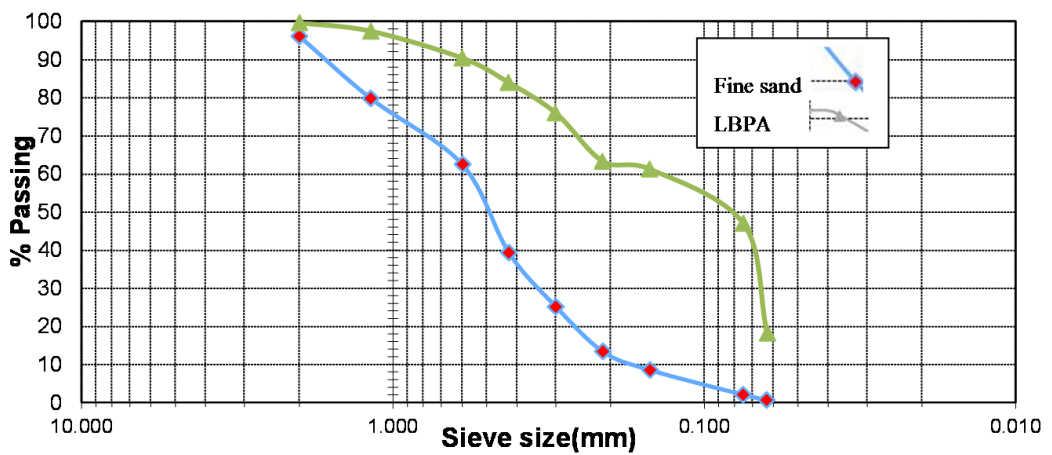

Fig 1: Sieve analysis of LBPA and sand

Fine sand aggregate: The sand used for the study was sourced locally and it conforms to (ASTM C778-17, 2017). Sieving was done and the gradation of both fine sand and LBPA has seen in Figure 1.

Cement: Ordinary Portland cement that conforms to type 1 (ASTM C150 / C150M-18, 2018) was used and mixed with water, sand, LBPA and superplasticiser. The chemical composition of both cement and LBPA is shown in table 1 .

\begin{tabular}{ccc} 
Table 1: Chemical composition of cement and LBPA \\
\cline { 2 - 3 } Oxides & LBPA & Cement \\
\hline $\mathrm{SiO}_{2}$ & 40.25 & 20.70 \\
$\mathrm{Al}_{2} \mathrm{O}_{3}$ & 13.15 & 5.75 \\
$\mathrm{Fe} 2 \mathrm{O} 3$ & 9.00 & 2.50 \\
$\mathrm{CaO}$ & 12.50 & 64.00 \\
$\mathrm{MgO}$ & 2.03 & 1.00 \\
$\mathrm{SO}_{3}$ & 1.50 & 2.75 \\
Loss of ignition & 6.05 & 2.30 \\
\hline
\end{tabular}

Admixture: The super-plasticizer (SP) used was Hydroplast - 300, a third generation high performing polycarboxylate ether super-plasticizer with great water reducing properties which allow for the production of high consistency mixed concrete with the low water-cement ratio. It also ensures extended workability and improves early and final strength development.

Mixture proportioning: Five different mortar mixes were designed for the experiment as shown in Table 2.
Replacement levels of $0 \%, 10 \%, 15 \%, 20 \%$ and $30 \%$ of cement mass were used. The water: cement binder ratio was maintained at 0.55 , and a constant dosage of $1 \%$ of cement of SP to enhance the workability of the mortar. Mortar samples were prepared for scanning electron microscopy and energy dispersive spectroscopy (SEM/EDS) as well as for X-ray Diffraction (XRD) analysis.

Table 2: Mix design of mortar $\left(\mathrm{kg} / \mathrm{m}^{3}\right)$

\begin{tabular}{llllll}
\hline \multicolumn{2}{l}{ Mixture code Cement LBPA } & Sand & Water & SP (grams) \\
\hline Control (C) & 628.3 & - & 1256.4 & 341.5 & - \\
A & 565.5 & 62.8 & 1132.3 & 314.2 & 5.7 \\
B & 534.1 & 94.2 & 1069.7 & 297.3 & 5.3 \\
D & 502.6 & 125.7 & 1006.1 & 279.2 & 5.0 \\
E & 439.8 & 188.5 & 880.2 & 244.3 & 4.4 \\
\hline
\end{tabular}

Preparation and casting of samples: Dry mixing was first performed for both cement and sand manually for 3 minutes; thereafter the LBPA was mixed until a homogeneous mix was obtained. A liquous superplasticizer solution was prepared and added to the mix. The mix was continuously stirred and water was added gradually until a homogeneous mix was obtained (uniformity in colour and consistency). A total of twelve $50 \mathrm{~mm}$ cube specimens were batched, demoulded and cured for 7, 14, 21 and 28 days in a curing tank containing water at $23^{\circ} \mathrm{C}$ respectively.

Testing programme: The adopted testing method used is setting time (ASTM Standard C807-13, 2013), 
workability (ASTM Standard C1437-15, 2015). In the same vein, the samples were tested for compressive strength (ASTM Standard C109M-16, 2016) after 7, 14,21 and 28 days of water curing.

Characterisation of blended cement mortars: The fractured samples were examined using a field emission scanning electron microscope (FESEM) (model: JSM-7600F, Jeol, Japan) at an acceleration potential of $15 \mathrm{kV}$. The fractured surfaces of the specimens were sputter-coated with a thin layer of platinum using a JFC-1600 auto fine coater. The EDS results were obtained using the same model of SEM machine.

$X$-ray diffraction Analysis for Mineral Identification: Powdered samples were pelletized and sieved to $0.074 \mathrm{~mm}$. These were later taken in an aluminum alloy grid $(35 \mathrm{~mm} \times 50 \mathrm{~mm})$ on a flat glass plate, covered with a paper and the samples were compacted by gently pressing them with the hand. Each sample went through the Rigaku D/Max-11lC X-ray diffractometer developed by the Rigaku Int. Corp. Tokyo, Japan and set to produce diffractions at a scanning rate of $20 / \mathrm{min}$ in the 2 to 500 at room temperature with a $\mathrm{CuKa}$ radiation set at $40 \mathrm{kV}$ and $20 \mathrm{~mA}$.

\section{RESULTS AND DISCUSSION}

Workability: The results of the fresh concrete properties of the LBPA mortars in Figure 2 indicated a satisfactory flow of slump in the range between 14 $\mathrm{mm}$ and $49 \mathrm{~mm}$. The least workability was gotten at the highest percentage of $30 \%$ LBPA, while the control mix was observed to have the highest slump flow. The flow rate obtained in both cases could be as a result of reduced workability with increase in LBPA content in the mortar mix. This reduction in the flow rate recorded was similar to the flow rate reported by Tangchirapat et al. (2009), that an increase in ash content leads to a progressive decrease in workability.

The slump values of samples E, D, B and A decreased $250 \%, 69 \%, 44 \%$ and $23 \%$ respectively as compared to control slump value.

This reduction in slump on increase of LBPA could be attributed to the porous nature it was due to the presence of macro and mesopores located within and on the surface of the material which led to its substantial specific surface area. The LBPA will after that absorb some amount of water unto its surface during mixing which would cause a subsequent reduction in free water and a lower slump value (Cordeiro et al., 2012).

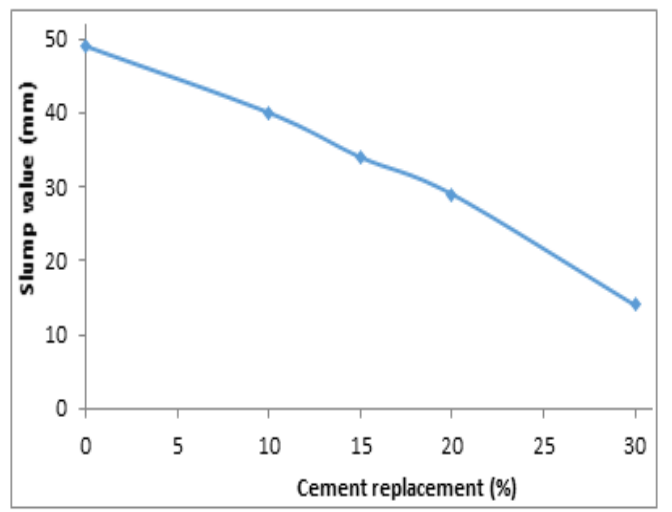

Fig 2: Slump values of fresh concrete

Initial and final setting times: Figure 3 shows the final and initial setting times. An observed increase in both initial and final setting times as the cement binder replacement increases was noted. At $30 \%$ replacement, the LBPA blended cement mortar increased the initial setting time by $66.8 \%$, while the same replacement level increased the final setting time relative to the control by $39.7 \%$. The fineness (amorphous or crystalline) of the LBPA powder determines both setting times. The nature of the LBPA is dependent on the temperature during the ashing process as low ashing temperature would yield crystalline powders such as from open burning while high temperature would produce amorphous powders (Tangchirapat et al., 2009). Another reason adduced for this pattern is that the low rate of cement hydration in the paste consisting of the LBPA pozzollan led to an increase in both initial and final setting times on subsequent increase in cement replacement levels (Cordeiro et al., 2012).

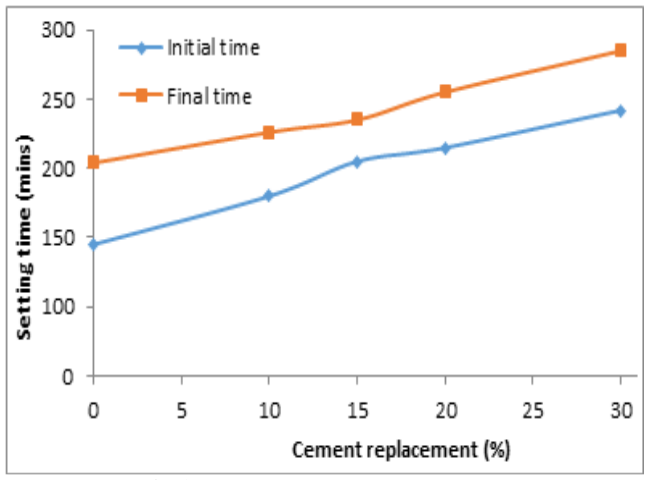

Fig 3: Initial and final setting times

Compressive strength: The compressive strength in relation to the LBPA cement replacement levels and specimen age (7, 14, 21 and 28 days) is shown in Figure 4. The mean compressive strength was $22.5 \pm 4.86, \quad 14.27 \pm 1.99,13 \pm 4.96, \quad 14.8 \pm 4.09$ and 
$10.8 \pm 0.63$ for $0,10,15,20$ and $30 \%$ cement replacement with LBPA respectively. As seen in Fig. 4 , there was an increase in strength up till the $15 \%$ replacement level then a reduction in the values was noticed. At 7 days the compressive strength ranged $21.3-38.4 \mathrm{MPa}$ at 0 to $15 \%$ replacement levels however, from $20 \%$ to $30 \%$ cement replacement, a decrease in values from 24 to $23 \mathrm{MPa}$ was observed. Similar trends were observed at 14, 21 and 28 days where the peak strength was at $15 \%$ cement replacement. The results are comparable to ChaoLung et al. (2011) who reported that the optimum compressive strength was obtained at $15 \%$ cement replacement but decreased on increase in cement replacement beyond 20\%. This improvement is related to reduced pores and increased Calcium silicate hydrate (C-S-H)compound in the matrix which resulted into the formation of a dense mortars after the early curing days (Raman et al., 2011). The data from this experiment was compared with similar studies conducted using agro-waste based ash as cement replacement to relate the effects of cement replacement and the age to the compressive strength as shown in Table 3.

Table 3: Comparison with compressive strength of other agrowaste ashes studied

\begin{tabular}{lcccc}
\hline $\begin{array}{c}\text { Agro waste } \\
\text { ash }\end{array}$ & $\begin{array}{c}\text { Optimal } \\
\%\end{array}$ & $\begin{array}{c}\text { Super- } \\
\text { plasticizer }\end{array}$ & Age & $\begin{array}{c}\text { Comp. Stre. } \\
\text { (MPa) }\end{array}$ \\
\hline LBPA- P.S. & 15 & Yes & 28 & 65 \\
Bagasse & 10 & No & 90 & 68 \\
Palm oil fuel & 10 & No & 28 & 5.5 \\
Rice husk & 15 & Yes & 28 & 51 \\
Banana leaf & 7.5 & Yes & 91 & 42 \\
Bamboo leaf & 20 & No & 28 & 56 \\
\hline P.S. - present study & & &
\end{tabular}

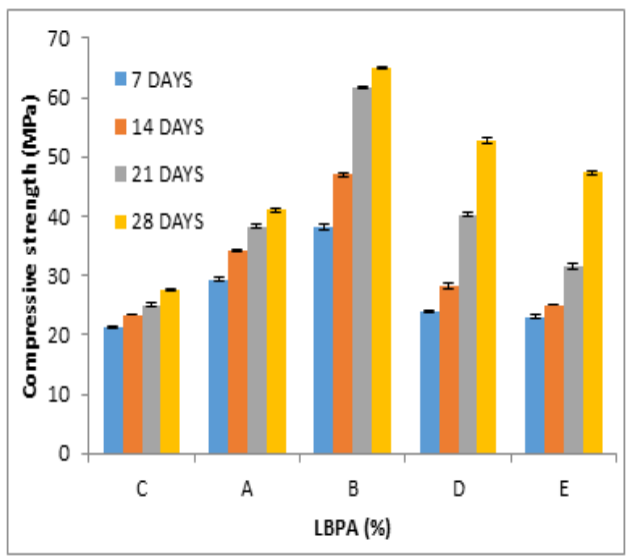

Fig 4: Compressive strength of LBPA blended mortars

Almost any research conducted on the use of agrowaste material in green concrete included compressive strength or strength activity index as one of the properties evaluated. The reason is that it is one of the significant features used in the design of mortars and concrete for various load applications and as well as a form of field quality control assessment. From the analysis of the comparison shown in table 3 , the compressive strength was in the range $42-68 \mathrm{MPa}$ across different curing days, this is comparable to $65 \mathrm{MPa}$ obtained in this study. In the same vein, the optimal cement replacement across these studies varied from $7.5 \%-20 \%$, which is in tandem with the optimal cement replacement of $15 \%$ recorded in this work as well. Some researchers have noted that mortars incorporated with supplementary cementitious materials (SCM) tend to develop later strength which would be higher than the control samples without SCM replacement (Raman et al., 2011; Chopra and Siddique, 2015). Most of the high compressive strength results that were observed at the later curing days starting ranged from 28 days to 91 days as seen in table 3 rather than early curing days, which could range from 3 days to 21 days.

Characterisation of LBPA blended cement mortars: Scanning electron microscope (SEM): The micrograph of the surfaces of $10 \%$ (A), $15 \%$ (B) and $20 \%$ (D) LBPA mortar samples after 28 days of curing is shown in Figure 5. Fig. 5(a) showed the presence of both micro and macro pores of the sample with $10 \%$ LBPA content and C-S-H gel could also be sighted in it. These pores are largely caused by evaporation of water during hydration based on the LBPA content in the sample. It has been stated that agro-based ashes used as cement replacement tend to absorb free water into its pores during mixing and this is released at the later stages when the relative humidity of the cement drops. This should cater for the drop in water requested for hydration to be completed, but where this free water is not available in required quantity, porous surface may emerge as might be this case under consideration (Chopra and Siddique, 2015; Mahmud et al., 2016). The presence of these voids mostly led to the poor compressive strength performance of the sample. However, in Fig. 5(b), mix with 15\% LBPA replacement could be seen, reduced voids on the surface could be observed due to hydration improvement, and likewise, large occurrence of C-S$\mathrm{H}$ gels could be noticed as well on the surface. This could be the reason for the optimal compressive strength gotten at this mix level. The increase in LBPA content could improve the pore characteristics because it led to a higher amount of C-S-H gel formation during the pozzolanic reaction which contributed to the refinement of pore structure subsequently leading to volume reduction of large pores and porosity of the mortar. Figure 5(c), is the micrograph of $20 \%$ LBPA replacement, it was noted the mix commenced disintegration at the quantity of LBPA was increased; 
this perhaps led to the reduction in compressive strength. Ettringites are the needle-like crystals that are developed in vacant spaces during hydration also led to a weakening of the concrete strength as well.
Some portions of incompletely hydrated cement particles were also identified, this also contributed to lower strength of the mortars.

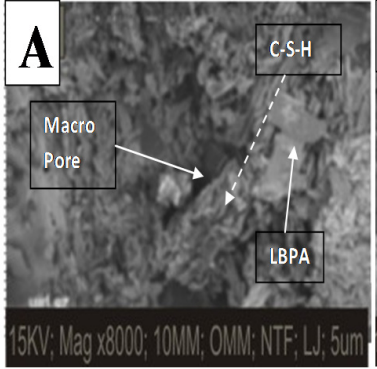

(a) $10 \% \mathrm{LBPA}$

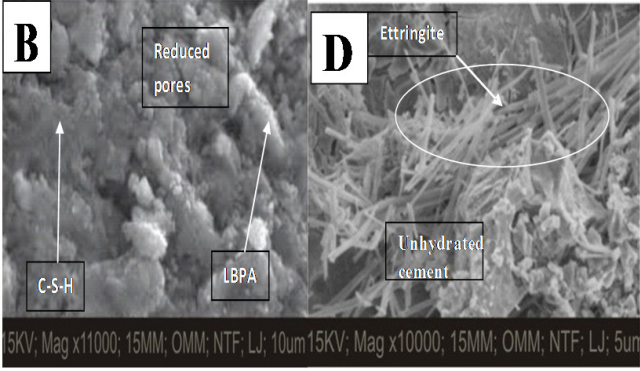

(b) $15 \%$ LBPA

(c) $20 \%$ LBPA

Fig 5: SEM images of mixes A, B and D

Energy Dispersive Spectroscopy (EDS): It is seen in Figure 6 that mix B contains $34 \%$ of Silica, while mix $\mathrm{A}$ and D show $8.28 \%$ and $6.28 \%$ respectively. Also, mix B contains $14.4 \%$ of calcium, while A and D are $35.60 \%$ and $35.62 \%$ as well. Only mix B had $20.2 \%$ of Alumina while the rest had none. This result validates the presence of $\mathrm{C}-\mathrm{S}-\mathrm{H}$ in the SEM micrograph for mix $\mathrm{B}$. The selected region in sample $\mathrm{B}$ had gel composition of $\mathrm{Si} / \mathrm{Ca}=2.36$ and $\mathrm{Al} / \mathrm{Ca}$ equivalent to 1.40 , while $\mathrm{Si}-\mathrm{Ca}$ relationship of 0.23 and 0.18 was recorded for mix A and D. Alumina was, however, absent from the composition of the mixtures. The presence of C-S-H gel compound in mix B greatly helped to improve the compressive strength much more than the other mixes. A clear difference in the proportion of $\mathrm{Si} / \mathrm{Ca}$ gel phase among $\mathrm{B}, \mathrm{A}$ and $\mathrm{D}$ could be spotted.

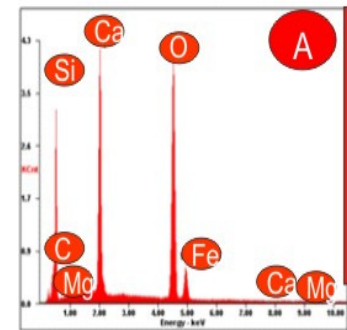

(a) $10 \%$ LBPA

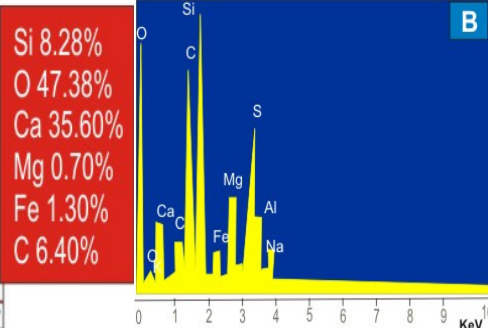

(b) $15 \%$ LBPA

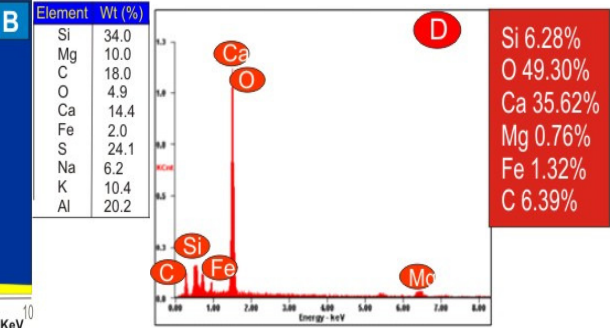

(c) $20 \%$ LBPA

Fig 6: EDS of A, B and D mortar mixes

$X$-ray diffraction analysis: The XRD diffraction patterns of two samples A and D are shown in Figures 7 - 8. Sample A has calcite with silica were the dominant peak at $17.5^{\circ} \mathrm{C}$, which is within the amorphous temperature range of 10 to $20^{\circ} \mathrm{C}$ respectively for the $2 \Theta$ range.

This temperature range is favourable for the pozzolanic activity of the compound. Crystalline compounds such as silica, cristoballite, and gismondine are the other significant peaks noted at $25.8^{\circ}, 33^{\circ}$ and $47^{\circ}$ respectively.

However, sample D had significant peaks at 27.5, 35 and 42.5 which belong to crystalline compounds such as calcite and silica.
These compounds played a significant role in the decrease of the compressive strength as seen from the compressive test because of their crystalline forms which originated from the slow rate of cooling of the LBPA within the furnace during the calcining process.

Conclusion: This work concludes that mortar fresh properties results indicated that workability reduces as LBPA increases in the concrete mix. However, increase in both initial and final setting times as the cement binder replacement increases were noted. Increase in LBPA content led to a progressive increment in compressive strength up to $15 \%$ replacement of cement. But further increase in LBPA content beyond this level led to a subsequent decrease in strength because of the lower cement composition and slow hydration process. 


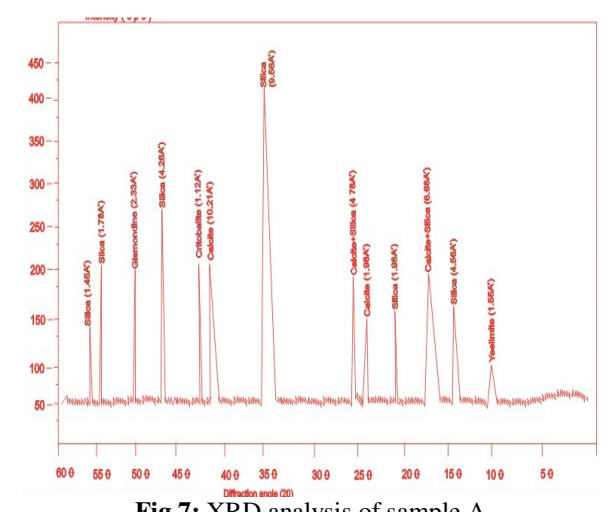

Fig 7: XRD analysis of sample A

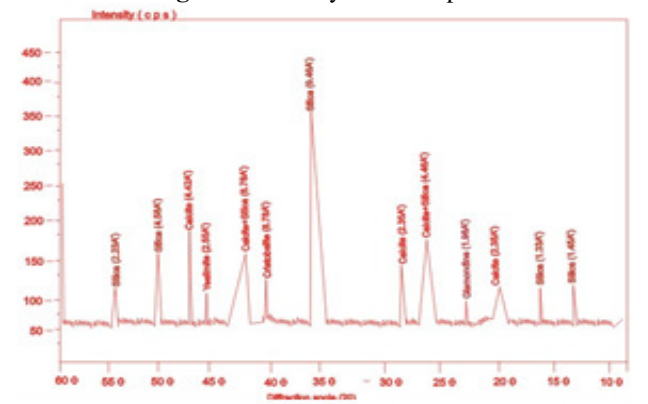

Fig 8: XRD analysis of sample D

The obtained compressive strength of this study was within the reported range of other studies conducted on supplementary cementitious materials from agricultural wastes that were used as cement replacement. SEM, EDS, and XRD showed the pronounced presence of CSH gel in the 15\% LBPA replacement of cement more than the other samples which helped to explain the highest compressive strength obtained at the same replacement level.

\section{REFERENCES}

Adama, A. Y., and Jimoh, Y. A. (2012). Effect of locust bean pod ash on strength properties of weak soils. $A U$ Journal of Technology, 16(1), 21-35.

Akpenpuun, T. D., Adeniran, K. A., and Okanlawon, O. M. (2017). Rattan Cane Reinforced Concrete Slab as a Component for Agricultural Structures. Nigierian Journal of Pure and Applied Science, 30(1), 3007 3013. doi:http://dx.doi.org/10.19240/nipas.2017.A20

ASTM C150 / C150M-18. (2018). Standard Specification for Portland Cement. West Conshohocken, PA.: ASTM International.

ASTM C778-17. (2017). Standard Specification for Standard Sand. West Conshohocken, PA.: ASTM International.
ASTM E986 - 04. (2017). Standard Practice for Scanning Electron Microscope Beam Size Characterisation ASTM International (10.1520/E0986-04R17 ). West Conshohocken, PA.

ASTM Standard C109M-16. (2016). Test Method for Compressive Strength of Hydraulic Cement Mortars (Using 2-in. or [50-mm] Cube Specimens: ASTM International.

ASTM Standard C807-13. (2013). Test Method for Time of Setting of Hydrualic Cement Mortar by Modified Vicat Needle. West Conshohocken, PA: ASTM International.

ASTM Standard C1437-15. (2015). Test Method for Flow of Hydraulic Cement Mortar. West Conshohocken, PA: ASTM International.

Chao-Lung, H., Le Anh-Tuan, B., and Chun-Tsun, C. (2011). Effect of rice husk ash on the strength and durability characteristics of concrete. Construction and Building Materials, 25(9), 3768-3772.

Chopra, D., and Siddique, R. (2015). Strength, permeability and microstructure of self-compacting concrete containing rice husk ash. Biosystems Engineering, 130, $72-80$.

Cordeiro, G. C., Toledo Filho, R. D., Tavares, L. M., and Fairbairn, E. M. R. (2012). Experimental characterization of binary and ternary blended-cement concretes containing ultrafine residual rice husk and sugar cane bagasse ashes. Construction and Building Materials, 29, 641-646.

Mahmud, H., Bahri, S., Yee, Y., and Yeap, Y. (2016). Effect of rice husk ash on strength and durability of high strength high-performance concrete. International Journal of Civil and Environmental Engineering, 10(3), 390-395.

Omoniyi, T. E., and Akinyemi, B. A. (2012). Durability based suitability of bagasse-cement composite for roofing sheets. Journal of Civil Engineering and Construction Technology, 3(11), 280-290.

Raman, S. N., Ngo, T., Mendis, P., and Mahmud, H. B. (2011). High-strength rice husk ash concrete incorporating quarry dust as a partial substitute for sand. Construction and Building Materials, 25(7), 3123-3130.

Röbler, C., Bui, D. D., and Ludwig, H. M. (2013). Mesoporous structure and pozzolanic reactivity of rice husk ash in cementitious system. Construction and Building Materials, 43, 208-216.

Tangchirapat, W., Jaturapitakkul, C., and Chindaprasirt, P. (2009). Use of palm oil fuel ash as a supplementary cementitious material for producing high-strength concrete. Construction and Building Materials, 23(7), 2641-2646. 